\title{
Caries del Biberón
}

\author{
Antonia Molina Escribano ${ }^{a}$, Antonio J. López Garvíb. Catalina López Ibáñez ${ }^{c}$, Úrsula Sáez Cuestad
}

\begin{abstract}
a Odontóloga de área del Centro de Salud de Casas Ibáñez (Albacete) y de la Unidad de Salud Bucodental (USBD) de Discapacitados de Albacete.

b Odontólogo de área del Centro de Salud de Almansa.

${ }^{\mathrm{c}}$ Higienista dental de área del Centro de Salud de Casas lbáñez y de la USBD de Discapacitados de Albacete.

${ }^{d}$ Odontóloga de área de Albacete y de la USBD de Discapacitados de Albacete.
\end{abstract}

Correspondencia: Antonia Molina Escribano. C/ Pablo Medina 7, $6^{\circ} \mathrm{A}, 02005$ - Albacete. Telf.: 666307128, e-mail: antomolinaescribano@yahoo.es

Recibido el 1 de agosto de 2007.

Aceptado para su publicación el 30 de octubre de 2007.

\section{RESUMEN}

La caries del biberón es una enfermedad de evolución rápida y agresiva que afecta a la dentición temporal de niños de muy corta edad en los que la alimentación con biberón se ha prolongado más allá del tiempo recomendable. El estancamiento de la leche o de otros líquidos azucarados en la boca del niño, unido a la falta de higiene oral, produce este tipo de lesiones, que dan lugar a una odontodestrucción severa. En el presente artículo presentamos el caso de un niño de tres años de edad que padece la citada patología y hacemos un análisis de sus causas y consecuencias.

Palabras clave. Caries dental. Dentición primaria.

\section{ABSTRACT}

\section{Nursing bottle caries}

Nursing bottle caries is a quick and aggressively developing disease that affects primary dentition of very young children fed with a nursing bottle for longer than recommended. These lesions are caused by the milk or other sugared liquids held for a time inside the child's mouth and deficient oral hygiene and can result in severe caries. In this article we present this condition in a three-year-old child and we analyze its etiology and consequences.

Key words. Dental caries. Dentition primary.

\section{INTRODUCCIÓN}

El término "caries del biberón" se utiliza para designar un proceso careoso de evolución agresiva y rápida que afecta a la dentición temporal de niños de corta edad y que suele tener su inicio en las superficies lisas del diente, poco susceptibles a padecer caries en circunstancias normales. Este cuadro clínico se presenta, sobre todo, en niños que suelen dormir con el chupete impregnado en sustancias azucaradas (miel, azúcar, leche condensada, etc.) o en aquéllos que toman el biberón de leche o zumo acostados. El niño se duerme y la leche o líquido azucarado se acumula alrededor de los dientes, brindando un excelente medio de cultivo para los microorganismos acidógenos (estreptococo mutans), y esto, unido a la disminución del flujo salival que se produce durante el sueño, agrava la situación y da lugar a un ambiente altamente cariogénico ${ }^{1}$ que propicia así la aparición de caries agresivas, de localización preferente en el maxilar superior, siendo los incisivos superiores los dientes más afectados. Cuando el hábito es diurno, se afectan menos los incisivos superiores y aparecen caries en lingual de molares mandibulares.

\section{OBSERVACIONES CLÍNICAS}

El caso que nos ocupa es el de un niño de tres años de edad que presenta un cuadro característico de caries del biberón. La disposición de las lesiones refleja los lugares donde los hidratos de carbono quedan depositados, bañando y lesionando superficies dentarias poco propensas a la caries².

Existe afectación extrema de los dientes anterosuperiores y de los primeros molares temporales superiores e inferiores. De hecho, de estos dientes quedan en boca tan sólo los restos radiculares (figura 1). Debido a la secuencia eruptiva, los caninos y segundos molares temporales están menos afectados y fue posible realizar un tratamiento odontológico conservador mediante la obturación con resinas estéticas de composite. Los incisivos inferiores no están afectados, ya que están protegidos por el labio inferior 
y la lengua, y cuentan, además, con otro mecanismo protector: la autolisis ejercida por la saliva proveniente de las glándulas sublinguales ${ }^{3}$ (figura 2).

Debido a la rápida destrucción del tejido dental, la pulpa queda afectada de forma precoz. Por tanto, la caries de biberón, si no es tratada a tiempo, llega a causar una serie de problemas: dolor por afectación pulpar, problemas estéticos, dificultad para la fonación y la masticación, instauración de hábitos nocivos como la interposición lingual o labial y malposición dentaria por alteración de la erupción de los dientes permanentes que les suceden. El objetivo de nuestro tratamiento será evitar, en lo posible, la aparición de todos estos inconvenientes, pero las posibilidades terapéuticas, en muchos casos, se encuentran limitadas por lo avanzado de las lesiones y por la corta edad de los pacientes, cuya colaboración se hace muy difícil en tratamientos tan laboriosos como los que precisan ${ }^{4}$. Esto fue lo que nos llevó, en el caso que nos ocupa, a decantarnos por el tratamiento mediante anestesia general.

\section{DISCUSIÓN}

En la prevención de la caries del biberón es primordial la concienciación de los padres acerca de la etiología del problema. Según la Academia Americana de Pediatría (AAP, 1985), se debe interrumpir la lactancia materna y comenzar a administrar el biberón a los nueve me-

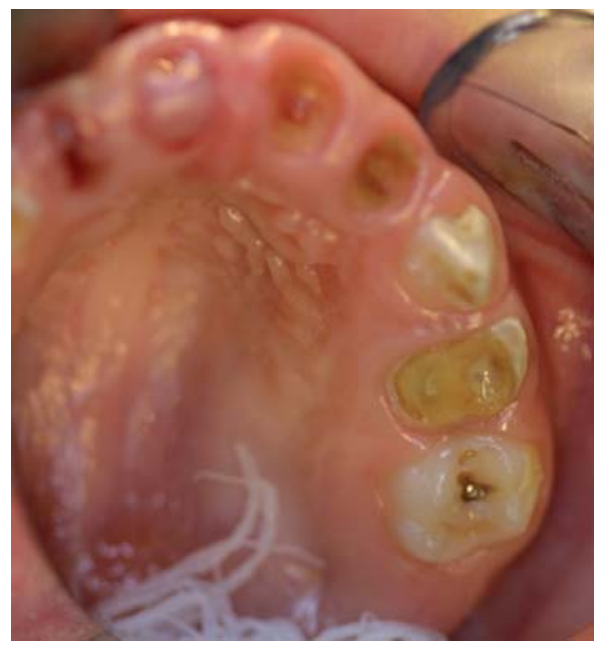

Figura 1. Afectación extrema de los dientes anterosuperiores y de los primeros molares temporales. ses, y finalizarlo a los doce meses con la introducción completa de la alimentación sólida, que permite todas las ventajas de la masticación (autolisis, eliminación de la succión que puede deformar el paladar, etc.). Sin embargo, son muchos los padres que no están dispuestos a someterse al estrés del destete temprano o de la retirada total del biberón.

Es muy importante explicar a los padres que, para dar el biberón a su bebé, este debe estar incorporado y que deben limpiar los dientes tras la ingesta, no permitiendo, en ningún caso, que el bebé se acueste sin haber realizado la higiene oral. Otra recomendación básica es la de limitar, en lo posible, el consumo de sacarosa entre las comidas y no utilizar sustancias con potencial cariogénico elevado (miel, azúcar, leche condensada, mermelada, etc.) para impregnar el chupete o la tetina del biberón.

Para la mayoría de los autores, la leche constituye el factor causal más importante de la caries del biberón, siempre y cuando se tome de una forma regular durante más tiempo del considerado normal para el destete ${ }^{5}$. Los zumos de fruta azucarados que los padres dan a los niños por su alto contenido en vitamina $\mathrm{C}$ y su agradable sabor también tienen un alto contenido en azúcares y un efecto cariogénico mucho mayor que la propia leche ${ }^{6}$.

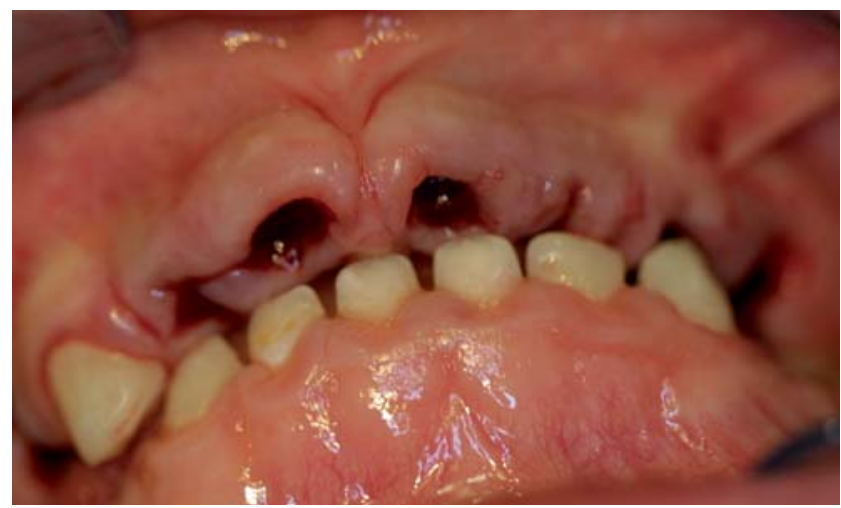

Figura 2. Incisivos inferiores no afectados, ya que están protegidos por el labio inferior y la lengua.

\section{BIBLIOGRAFÍA}

1. Mc Donald RE, Avery DR. Odontología Pediátrica y Del Adolescente. Buenos Aires: Ed. Panamericana; 1990.

2. Ostos MJ, González E, Menéndez M. Patrones de caries dental en el niño preescolar. Odontología Pediátrica 1992; 1:171-81.

3. Yiu CK, Wei SHY. Management of rampant caries in children. Quintessence International 1992; 23:159-68.

4. Pinkman JR. Linguistic maturity as a determinant of child patient behaviour in dental office. J Dent Child 1997; 5:3226.

5. Dilley GS, Dilley DH, Machen JB. Prolonged nursing habit: a profile of patients and their families. J Dent Child 1980; 47:102-8.

6. Smith AJ, Shaw C. Baby fruits juices and tooth erosion. British Dental Journal 1987; 162:65-7. 